\title{
Clinical care for obesity: a preliminary survey of 68 countries
}

Rachel Jackson Leach ${ }^{1}$

Jaynaide Powis ${ }^{1}$

Louise A Baur ${ }^{2}$

Ian D Caterson ${ }^{3}$

William Dietz ${ }^{4}$

Jennifer Logue $e^{5}$

Tim Lobstein ${ }^{1,3}$

${ }^{1}$ World Obesity Federation, World Obesity Federation, 107-111 Fleet Street, London EC4A 2AB, UK.

${ }^{2}$ Discipline of Child and Adolescent Health, University of Sydney, New South Wales 2006, Australia.

${ }^{3}$ The Boden Collaboration, Charles Perkins Centre, The University of Sydney, New South Wales 2006, Australia.

${ }^{4}$ Sumner M Redstone Global Center for Prevention and Wellness, Milken Institute School of Public Health, George Washington University, Washington, DC 20052, USA.

${ }^{5}$ Lancaster Medical School, Furness Building, Lancaster LA1 4YG, UK.

\section{Correspondence:}

Tim Lobstein, World Obesity Federation, World Obesity Federation, 107-111 Fleet Street, London EC4A 2AB, UK.

Email: tlobstein@worldobesity.org

\section{Funding information}

Funding included an unrestricted educational grant from Novo Nordisk A/S, Denmark made to the World Obesity Federation.

\section{Summary}

Obesity is a chronic relapsing condition affecting a rapidly increasing number of people worldwide. The United Nations has stated that universal health coverage is an essential element of the globallyagreed sustainable development goals. This paper provides a preliminary report of a survey of relevant health professionals and other interest groups on the readiness of health systems to provide obesity treatment services. Interviews and questionnaires were completed by 274 respondents from a total of 68 low, middle and high income countries. Respondents in the majority of countries stated that there were professional guidelines for obesity treatment, but that there was a lack of adequate services, especially in lower income countries, and in rural areas of most countries. Lack of treatment was attributed to a broad range of issues including: no clear care pathways from primary care to secondary services; absent or limited secondary services in some regions; lack of trained multi-disciplinary support professionals; potentially high costs to patients; long waiting times for surgery; and stigma experienced by patients within the health care services. Defining obesity as a disease may help to overcome stigma and may also help to secure better funding streams for 
treatment services. However, the survey found that few countries were ready to accept this definition. Furthermore, until countries fully adopt and implement obesity prevention policies the need for treatment will continue to rise while the necessary conditions for treatment will remain inadequate.

\section{KEY WORDS}

treatment, coverage, barriers, health systems, survey, international

\section{INTRODUCTION}

Worldwide, the prevalence of obesity in the adult population rose during the last decade and without significant interventions will increase further in the coming decade. In 2011 the United Nations General Assembly agreed a Political Declaration on the Prevention and Control of NonCommunicable Diseases (NCDs), that called on member states to achieve by 2025 a $25 \%$ reduction in mortality for NCDs and no increase in the prevalence of adult obesity or diabetes above 2010 levels. ${ }^{1}$ In 2019, the General Assembly adopted a Political Declaration promoting universal health coverage for achieving the sustainable development goals. ${ }^{2}$ The World Health Organization (WHO) estimates that an additional USD200 billion a year invested in scaling up primary health care across low and middle income countries would potentially save 60 million lives, increase average life expectancy by 3.7 years by 2030 , and contribute significantly to socio-economic development. ${ }^{3}$ This investment would represent about 3\% increase on the USD7.5 trillion already spent on health globally each year.

By 2025, global obesity prevalence is predicted to reach $18 \%$ in men and surpass $21 \%$ in women. ${ }^{4}$ Of these, an estimated $257 \mathrm{~m}$ adults worldwide ( $6 \%$ of men and $9 \%$ of women) are forecast to be living with severe obesity (defined here as a body mass index $>34.9 \mathrm{k} / \mathrm{m} 2$ or more) in 2025 , showing a rapid increase from an estimated $173 \mathrm{~m}$ in $2014 .{ }^{5}$ These projections indicate a significant need for treatment provided by national health services. Left untreated, the consequences of obesity are likely to escalate, as the duration of obesity increases the likelihood of more disabling diseases requiring greater intensity of interventions. ${ }^{6,7}$

We report here the results of a series of semi-structured interviews and questionnaires with interested parties in a preliminary sample of 68 countries. The data collection was designed to 
assess the readiness of national health services to provide weight management and obesity treatment.

\section{METHODS}

A mixed methods approach was taken to data collection, using face-to-face interviews, online interviews and online questionnaires in seven languages (English, Arabic, French, German, Italian, Portuguese, and Spanish). Information was collected, interviews were conducted and questionnaires completed between May 2018 and August 2019.

Respondents for interviews and online questionnaires were recruited through World Obesity Federation member organisations, social media (Twitter, LinkedIn), other professional society newsletters and authorship of relevant published papers. All coherent responses were considered valid for inclusion in the analyses, including partially completed responses, and although respondents were asked to state their occupation, no attempt was made to stratify the analyses by respondents' training or experience

For the purposes of analysis, we have summarised the key issues relating to obesity management according to country income level, country health care expenditure (higher and lower tertiles) and anticipated adult obesity prevalence (higher and lower tertiles). For country income levels we combined data for low income and lower-middle income countries (here referred to as LLMI), to contrast with data for upper-middle income (UMI) and high income (HI) countries, according to World Bank income categories ${ }^{8}$ (see Table 1). Countries were also categorised according to their current national health care expenditure as a percentage of gross domestic product, provided by the World Bank ${ }^{9}$ with additional information from Hong Kong and Taiwanese government websites. Countries were divided into tertiles of low, middle and high health care expenditure (see Supplementary Table 1). Finally, countries were categorised into tertiles of lower, medium and higher predicted prevalence levels for severe obesity $(\mathrm{BMI}>34.9 \mathrm{~kg} / \mathrm{m} 2)$ in $2025^{5}$, (see Supplementary material).

The questions for survey and interview were developed and shared with the advisory committee then amended accordingly. A short preliminary survey was piloted, responses reviewed, and the protocol further extended and adapted. Variations in the survey were permitted in different regions and over time. Data were requested from respondents in several formats, included ratings, multiple 
choice answers and open-ended statements. Respondents were informed that their responses would be used anonymously in summary tables only. The interview and survey protocols are shown in Supplemental material.

Interview and questionnaire responses were analysed by two researchers separately and compared. Differing interpretations were discussed with a third researcher to reach agreement. Some respondents were re-contacted for clarification of their responses. An interview conducted jointly with two or more respondents was scored as a single response. When multiple responses were available for a given country, a consensus 'country description' was derived by agreement among the research team.

\subsection{Analyses}

Ratings were scaled from ' 0 ' (low rating) to '10' (high rating). When multiple respondents' ratings were available for a single country, a simple mean score was calculated. Groups of countries were compared non-parametrically using chi-squared for the sum of mean ratings: for example, for a given rating question, if the mean scores for three lower income countries were $3 / 10,4 / 10$, and $5 / 10$, while for four higher income countries the scores were $4 / 10,6 / 10,7 / 10$, and $8 / 10$, then a chisquared test compared the total score of $12 / 30$ for lower income countries with the total of $25 / 40$ for the higher income countries (in this case giving a chi-squared value of $3.48, \mathrm{p}=0.06$ ).

In the case where respondents were asked to identify what they considered to be the top five barriers to treatment in rank order, the responses were categorised by two researchers and reduced in two rounds to 30 specific barriers. These were then combined into country groups after adjusting for the number of respondents in each country, and rank ordered in frequency of mention,

Questions comparing services for rural populations were not used for countries where less than 5\% of the population live in rural areas (Singapore, Hong Kong, Kuwait, Qatar, and Belgium). ${ }^{10}$

\section{RESULTS}

Survey data were collected for 68 countries. Information for the United Kingdom was analysed separately for England and Scotland because the two regions have separate health care systems. Countries included 15 classified as low- and lower-middle income (LLMI), 23 as upper-middle 
income (UMI), and 30 as high income (HI). Semi-structured interviews and questionnaires were conducted with a total of 274 individuals, giving an average of just under four respondents per country, but with wide variation, ranging from a single respondent from each of 15 countries through to 20 respondents from Mexico alone (shown in Table 1). Professionals providing responses included many health service multi-disciplinary team members, as well as members of health advocacy organisations, patients and others (most of whom were researchers or student health care professionals) (Table 2).

\subsection{Available guidelines}

Respondents in forty-two of the countries stated that professional guidelines for weight management or obesity treatment were available for adults and/or children (Table 3 ). There was no difference in the proportion of countries with available guidelines across the income levels $\left(\mathrm{X}^{2}=\right.$ $3.99, \mathrm{p}=0.14$ - see Table 3 ). There was also no difference in the availability of guidelines between countries with high and low health care expenditure or between countries with high and low obesity prevalence (Table 3).

\subsection{Rating of health system}

Respondents were asked to rate the ability of the national health systems to care for people with obesity (Table 4). Based on ranking from 0 (very poor) to 10 (excellent), countries were typically scored at 4.2, or somewhat below the mid-point. Health systems in lower income countries tended to be given poorer scores than upper-middle and high income countries. Interestingly, countries with a higher level of health care expenditure scored significantly less well than those with lower health care expenditure $\left(\mathrm{X}^{2}=6.36, \mathrm{P}=0.01-\right.$ see Table 4$)$. There was no difference in scores between countries with higher and lower obesity prevalence rates (Table 4).

\subsection{Access to care services}

Four options for access to treatment were examined: via family physician referral, directly to specialist services, as a consequence of admission for complications, or via a screening exercise. Respondents in just over half of all countries (36 of 68) stated that access to care services was available via family physicians, while nearly half (30 of 68) stated that access was available following complications arising from obesity (Table 3). These are not mutually exclusive. In almost $15 \%$ of countries ( 10 of 68 ) access could be obtained through specialist services, and in 10\% (7 of 68) access was reportedly available through screening programmes. 
Access to care through family physicians differed according to country category: it was more frequently reported in high income countries compared with low income countries $\left(\mathrm{X}^{2}=7.90\right.$, $\mathrm{p}<0.02$ ) and in countries with higher obesity prevalence compared with countries with lower prevalence $\left(X^{2}=6.42, p<0.02-\right.$ see Table 3$)$. There was no difference between countries according to the level of their health care expenditure.

There were no differences between country categories for the proportions of respondents reporting access to obesity treatment following admission for complications (Table 3). Numbers were too small for statistical analysis of other routes of access.

\subsection{Urban versus rural services}

Respondents rated treatment availability in urban and rural areas. Ratings were generally lower in rural areas (average 2.3 points) than in urban areas (average 4.5 points) across all countries $\left(\mathrm{X}^{2}=\right.$ $67.17, \mathrm{p}<0.001$ - see Table 4). This finding was found consistently in lower and higher income, lower and higher health care expenditure, and lower and higher obesity prevalence categories (Table 4).

\subsection{Treatment not completed}

Respondents were asked an open-ended question about their experience of the reasons why patients may leave treatment or cease to use the provided services. The most common response was 'a failure to refer', followed by 'a lack of care pathways' (Table 3). Additional reasons given by respondents in at least ten countries were 'failure of treatment', 'lack of patient motivation or compliance', 'cost of treatment' and 'otherwise lost to follow-up'.

'Failure to refer' and 'lack of care pathway' were cited most often as the reason for uncompleted treatment in all categories of country: lower and higher income, low and high health care expenditure, and low and high obesity prevalence levels.

\subsection{Multi-disciplinary training}

Training in the various skills that make up a multi-disciplinary team capable of providing a range of treatment and weight management services appeared very inconsistent. Of 68 countries, 29 were reportedly provided adequate training of nutritionists and dietitians, but only four countries provided adequate training of paediatric obesity specialists. Rank ordering of the adequacy of training for different specialities was similar across the three categories of country income (Kendall 
concordance $\mathrm{w}=0.72, \mathrm{p}<0.05$ ), and country obesity prevalence (Spearman $\mathrm{r}=0.66, \mathrm{p}<0.05)$ but not for health care expenditure (Spearman $\mathrm{r}=0.35$, NS) (Table 3).

\subsection{Funding of treatment}

Regarding funding for obesity treatment, respondents gave multiple conflicting answers in some countries and answers that were unclear or could not be scored in others. Part of the difficulty may have been the ambiguity of definitions: in many countries the answer given may be 'out of pocket' although in some cases these costs may have been later reimbursed by insurance schemes. In some countries, multiple funding sources operate simultaneously for different population groups. In Mexico, for example, funding arrangements for public sector employees differ from those for private sector employees, and differ again for low income families. Within any funding source there may be variations in what would be funded and what the patient would have to pay.

\subsection{Barriers to treatment}

Respondents were asked to provide their 'top five' barriers to the provision of adequate treatment services. Responses were collated for each country and the tally for each of 30 identifiable responses calculated, after weighting to adjust for the number of respondents answering the question, to ensure that every country's contribution to the total was equal. The resulting scores are shown in Table 5. Most commonly stated barriers were 'lack of political will or interest', 'lack of trained professionals, and lack of training available', high costs of out-of-pocket payments', 'poor health literacy and poor behaviour', 'lack of recognition of obesity as a disease', and the prevailing 'obesogenic environment'.

Rank scoring of the barriers to treatment country categories showed strong correlational concordance between countries of different income levels, with Kendall's coefficient of concordance $\mathrm{w}=0.73(\mathrm{p}<0.001-$ see Table 5$)$. Despite the high concordance, inspection of Table 5 indicates several anomalies in the ordering of scores between the income categories. For LLMI countries, stigma and belief in individual responsibility ranked very low $\left(30^{\text {th }}\right)$ compared with HI countries (rank $2^{\text {nd }}$ ). Surprisingly, poor availability of pharmaceutical treatments ranked low in LLMI countries $\left(22^{\text {nd }}\right)$ possibly due to a lack of knowledge of the availability of such treatment, but relatively higher in UMI and HI countries ( $9^{\text {th }}$ and $11^{\text {th }}$ respectively). Similarly, lack of multidisciplinary teams ranked very low in LLMI countries $\left(29^{\text {th }}\right)$ but more highly in UMI $\left(14^{\text {th }}\right)$ and HI $\left(19^{\text {th }}\right)$ countries. 


\subsection{Moves to accept obesity as a disease}

Respondents were asked to assess their countries' recognition of obesity as a disease, both at the governmental level and among health care providers. Ratings averaged 5.0 (on a scale from 0 = 'not at all' to $10=$ 'yes completely') for both government and for service providers taking all countries together. There was some ambiguity in how respondents interpreted the phrase 'health care provider'. Some assumed this meant the clinical services or health professional bodies and some assumed it meant the funding agencies, such as health insurers. Any future survey should seek to disambiguate this phrase.

Respondents in low and lower-middle income countries gave a lower rating of their governments' move to defining obesity a disease compared with respondents in upper-middle and high-income countries $\left(\mathrm{X}^{2}=4.94, \mathrm{p}=0.08\right)$. Similarly, lower income countries gave lower ratings of their health care providers accepting obesity as a disease, compared with higher income countries $\left(\mathrm{X}^{2}=5.66\right.$, $\mathrm{p}=0.06$ ). Respondents in countries with lower health care expenditure gave a lower score for their governments' moves to accept obesity as a disease than countries with higher health care expenditure $\left(X^{2}=3.09, p=0.08\right)$. Otherwise, ratings for governments and health care providers did not differ by country categories.

\section{DISCUSSION}

The purpose of this study was to provide preliminary insights into the provision of services for the treatment of people with obesity. Over 270 partial or complete survey responses were collected from a total of 68 countries, including 15 low and lower-middle income countries, 23 upper-middle income and 30 high income countries. Respondents included a wide range of health care professionals and a small number of additional respondents from advocacy organisations, patients and others (largely research institutions and student health professionals).

The responses indicated that a majority of countries had professional guidelines for obesity treatment. The question was open-ended and included guidelines for the criteria for acceptance for bariatric surgery, general definitions for referral to secondary services by family physicians, or definitions to be used for screening in paediatric services. Government-approved guidelines appeared to be available for a few countries, while guidelines developed by health care professionals' organisations were available in more countries. 
Access to obesity treatment services was mainly though family physicians or as a result of treatment of obesity-associated complications. Higher income countries and countries with a higher prevalence of obesity appeared to have greater access to services through family physicians. For all categories of country, access to services was poorer in rural than urban areas.

Failure of treatment was explored with an open-ended question. Respondents identified 'failure to refer' and 'lack of care pathway' most frequently, across all country categories, indicating a serious shortfall in service provision available to most eligible patients. Treatment costs were also suggested as a disincentive for patients to adhere to treatment, along with treatment failure, suggesting that the forms of treatment may not be adequate, multi-disciplinary teams' skills may be insufficient or unavailable, or patient adherence may be overwhelmed by contextual factors in their family or social environments.

Training of professionals across the range of specialties needed for a multi-disciplinary team was considered poor in many countries and for many of the areas of expertise needed. Nutrition and dietetics professionals appeared to be most frequently trained staff groups, while training in paediatric obesity care was least. Lower income countries suffered from the lack of specialist training most acutely.

The costs to patients of obesity treatment were unclear. While out-of-pocket costs were widely acknowledged, the extent to which these might be refunded by insurance schemes was uncertain. Furthermore, countries appear to vary considerably in the forms of service available, what is funded by the state and what is available for lower income families. Further research is needed to obtain greater clarity on a country-by-country basis.

There was considerable agreement among respondents on the main barriers to successful treatment faced by people living with obesity. Most commonly cited in all country categories were a 'lack of political will or interest', a lack of trained professionals, high out-of-pocket costs and lack of investment in services. These responses emphasise the potential role of government and health care funding bodies to ensure better provision of services.

Also commonly stated as barriers to successful treatment were 'poor health literacy or behaviour' and also stigma and belief in individual responsibility. These responses describe an underlying attitude to obesity treatment held by health care professionals that emphasises the need for 
behaviour change and personal commitment, and the corollary assumption that treatment failure is a lack of commitment. Patients may react to these assumptions negatively and cease to attend treatment sessions in turn confirming the professionals' biases. ${ }^{11,12}$

For health professionals and some patients, classifying obesity as a disease may help overcome the assumption that obesity is an individual responsibility and that treatment failure reflects the lack of a personal commitment. Moves to have obesity formally accepted as a disease by governments, health professionals and health insurers were rated by respondents at an average of 5 points, midway on a scale from 0 (no moves) to 10 (fully accepted), but countries differed in ratings according to their level of economic development, with significantly lower ratings from respondents in low and lower-middle income countries.

A further commonly stated barrier to successful treatment was the 'obesogenic environment' which was seen as hampering long-term weight maintenance. It is increasingly recognised that successful weight maintenance during or after treatment depends on individuals being able to maintain healthpromoting diets and adequate physical activity, which is in turn influenced by the patient's social, financial, physical, and environmental circumstances. While additional questions were asked about prevention of obesity in national policies and practices, these are not reported here. Having such policies accepted at the national level may help improve the narrative from one of individual responsibility to one which recognises the social, environmental and commercial drivers of obesity and, to the extent that prevention policies can serve to reduce the obesogenicity of the environment, treatment for obesity and maintenance after weight loss may be more successful.

\subsection{Country categories}

The 68 countries were divided into categories according to World Bank income levels (gross national income per capita), health care expenditure as a proportion of GDP and projected prevalence levels of severe obesity among adults. Results were remarkably consistent across these categorisations although a few differences were noticeable: respondents in lower income (LLMI) countries tended to report poorer ability of their health services to care for people with obesity, and access to treatment for obesity was obtained more often as a part of treatment for complications of obesity rather than through family physician referral for obesity in itself. Lack of trained professionals or lack of training facilities were more often cited in LLMI countries. Moves to define obesity a disease were scored at a lower level in LLMI countries compared with upper-middle and high income countries. 
In countries differentiated by level of health care expenditure as a percentage of GDP, respondents showed similar responses to most questions. However, and perhaps contrary to expectations, respondents from countries with a higher level of health care expenditure gave a lower rating for their ability to provide care for people with obesity, and gave a lower score for their efforts to define obesity as a disease. It is possible that in better-funded health services the health care professionals responding to this survey had higher expectations and a greater sense of dissatisfaction with the services for people with obesity.

When countries were compared based on their level of severe adult obesity, responses were similar between higher and lower prevalence countries. Countries with a higher prevalence of severe obesity were more likely to offer access to services through family physicians compared to countries with lower prevalence levels.

\subsection{Limitations}

The preliminary insights provided by this survey are subject to a number of methodological concerns which we would attempt to rectify if this survey is to be extended. Firstly, we did not differentiate questions concerning secondary treatment services into sub-categories, such as pharmaceutical treatment, bariatric surgery, or various behaviour change approaches, nor investigate the provision of services for pediatric populations.

A second concern is that, while we successfully captured a wide range of responses across relevant professionals and interest groups, the result is a pool of information that has a limited capacity for categorical analyses. Respondents were self-selected, and there were too few members of any specialty, apart from nutritionists/dietitians, to allow comparison between respondent categories. The uneven response rate across the specialties may not have provided a representative view concerning the adequacy of services, training and referral pathways.

A third concern is the interpretation of results, especially where open-ended or potentially ambiguous questions were posed, and when respondents may not have been familiar with the language being used. This problem was especially noticeable in questions about funding of services, where there was some ambiguity on what was meant by 'out-of-pocket' and difficulty in generalizing when different population groups were funded differently. 
Throughout this research, the results collected and reported here are based on individuals' knowledge and views about the services available, rather than a direct assessment of the services themselves.

Lastly, it needs to be noted that attitudes towards obesity in lower and middle income countries will be complicated by the major nutritional transitions experienced in recent decades. The persistence of undernutrition and stunting, and the occurrence of both obesity and stunting in the same populations, will likely require different approaches to obesity treatment, despite the limited funds available. $^{12}$

\section{CONCLUSION}

United Nations member states have committed to advance towards universal health coverage by investing in key areas: to ensure no one suffers financial hardship because they have had to pay for healthcare out of their own pockets; implementing high-impact health interventions to combat disease; protecting women's and children's health; strengthening the health workforce and infrastructure; and reinforcing governance capacity ${ }^{13}$. This paper provides a preliminary report of the state of services for the treatment of obesity in a sample of countries, based on interviews and questionnaire responses provided by over 270 health professionals and interest groups. They report a lack of clear care pathways from family physician or other primary care service to secondary services, a lack of secondary, multi-disciplinary services, and potentially high costs to patients.

Attitudes that held patients responsible for their condition and their lack of commitment to treatment were also a concern, insofar as stigma experienced by patients can contribute to lack of treatment. Defining obesity as a disease may help to overcome stigma and improve patient referral and treatment adherence ${ }^{14,15}$ and may also help to secure better funding streams for treatment services, and for prevention services which are a necessary adjunct to reduce the risk of weight regain after treatment. ${ }^{16}$ However, many countries do not yet appear ready to recognise obesity as a disease, especially in lower income countries. Rapid changes will be needed in health systems worldwide in order to provide treatment for people living with obesity commensurate with the United Nations' goal of Universal Health Coverage.

\section{ACKNOWLEDGEMENTS}


The research reported here was overseen by an advisory committee: $\mathrm{N}$ Ahmad, O Barata Cavalcanti, S Barquera, E Govers, D Hatanaka, J Ralston, D Ryan, A Urudinachi. The authors are grateful for their contributions. The content of the present paper is the responsibility of the authors alone.

\section{CONFLICTS OF INTEREST}

Authors linked to the World Obesity Federation benefitted from an unconditional grant from Novo Nordisk A/S, Denmark. No conflicts of interest declared by other authors (TBC).

\section{AUTHOR CONTRIBUTIONS}

R.J.L. and J.P. undertook primary research, T.L. drafted the manuscript, L.A.B, I.D.C, W.D. and J.L. provided conceptual input and critically reviewed the manuscript.

\section{REFERENCES}

1. United Nations. Resolution adopted by the General Assembly A/RES/66/2. Political Declaration of the High-level Meeting of the General Assembly on the Prevention and Control of Noncommunicable Diseases. New York, 11 September 2011.

https://digitallibrary.un.org/record/710899/

2. United Nations. Resolution adopted by the General Assembly A/RES/74/2. Political Declaration of the High-level Meeting on Universal Health Coverage. New York, 23 September 2019. https://undocs.org/en/A/RES/74/2

3. World Health Organization. Countries must invest at least 1\% more of GDP on primary health care to eliminate glaring coverage gaps. News Release. Geneva, 22 September 2019. https://www.who.int/news-room/detail/22-09-2019-countries-must-invest-at-least-1-more-of-gdpon-primary-health-care-to-eliminate-glaring-coverage-gaps

4. NCD Risk Factor Collaboration. Trends in adult body-mass index in 200 countries from 1975 to 2014: a pooled analysis of 1698 population-based measurement studies with $19 \cdot 2$ million participants. Lancet, 2016;387:1377-96. 
5. World Obesity Federation. NCD Risk Factor Collaboration (op cit) data projected to 2025. London, 11 October 2018. http://s3-eu-west-1.amazonaws.com/woffiles/World_Obesity_Day_global_data_on_numbers_of_adults_affected.pdf

6. Abdullah A, Stoelwinder J, Shortreed S, et al. The duration of obesity and the risk of type 2 diabetes, Public Health Nutr 201;14:119-26.

7. Alpert MA, Lambert CR, Panayiotou H, et al. Relation of duration of morbid obesity to left ventricular mass, systolic function, and diastolic filling, and effect of weight loss, Am J Cardiol 1995;76:1194-97.

8. World Bank, online databases, 30 October 2019.

https://datahelpdesk.worldbank.org/knowledgebase/articles/906519-world-bank-country-andlending-groups.

9. World Bank, online databases, 30 October 2019.

https://data.worldbank.org/indicator/SH.XPD.CHEX.GD.ZS.

10. World Bank, online databases, 30 October 2019.

https://data.worldbank.org/indicator/SP.RUR.TOTL.ZS

11. Panza GA, Armstrong LE, Taylor BA, Puhl RM, Livingston J, Pescatello LS. Weight bias among exercise and nutrition professionals: a systematic review. Obes Rev. 2018;19:1492-1503. 12. Dietz WH, Baur LA, Hall K, Puhl RM, Taveras EM, Uauy R, Kopelman P. Management of obesity: improvement of health-care training and systems for prevention and care. Lancet. 2015;385:2521-33.

13. World Health Organization. News release. WHO welcomes landmark UN declaration on universal health coverage. 23 September 2019. New York. https://www.who.int/newsroom/detail/23-09-2019-who-welcomes-landmark-un-declaration-on-universal-health-coverage 14. Bray GA, Kim KK, Wilding JPH; World Obesity Federation. Obesity: a chronic relapsing progressive disease process. A position statement of the World Obesity Federation. Obes Rev. 2017;18:715-723.

15. Puhl R, Suh Y. Health Consequences of Weight Stigma: Implications for Obesity Prevention and Treatment. Curr Obes Rep. 2015;4:182-90. 
16. Lobstein T, Brinsden H, Gill T, Kumanyika S, Swinburn B. Comment: obesity as a disease some implications for the World Obesity Federation's advocacy and public health activities. Obes Rev. 2017;18:724-726. 
Table 1: Background data and number of interviews conducted in 68 countries

\begin{tabular}{|c|c|c|c|c|c|}
\hline & & $\begin{array}{c}\text { Predicted } \\
\text { percentage of } \\
\text { adults with BMI } \\
>=34.9 \mathrm{~kg} / \mathrm{m} 2 \text { in } \\
2025(1)\end{array}$ & $\begin{array}{c}\text { Predicted number } \\
\text { of adults with BMI } \\
>=34.9 \mathrm{~kg} / \mathrm{m} 2 \mathrm{in} \\
2025(1) \\
\text { Thousands }\end{array}$ & $\begin{array}{l}\text { Total health } \\
\text { expenditure } \\
\text { as \% GDP (2) }\end{array}$ & $\begin{array}{l}\text { Interviews / } \\
\text { questionnaires } \\
\text { conducted }\end{array}$ \\
\hline \multicolumn{6}{|c|}{ Low and lower-middle income } \\
\hline 1. & Bangladesh & 0.7 & 7,861 & 2.37 & 1 \\
\hline 2. & Cameroon & 4.6 & 682 & 4.69 & 5 \\
\hline 3. & Egypt & 15.5 & 9,970 & 4.64 & 4 \\
\hline 4. & El Salvador & 8.3 & 379 & 6.96 & 1 \\
\hline 5. & Ethiopia & 0.9 & 613 & 3.97 & 4 \\
\hline 6. & India & 0.9 & 8,246 & 3.66 & 12 \\
\hline 7. & Indonesia & 1.5 & 2,875 & 3.12 & 3 \\
\hline 8. & Kenya & 2.6 & 779 & 4.55 & 5 \\
\hline 9. & Morocco & 7.6 & 1,956 & 5.84 & 1 \\
\hline 10. & Myanmar & 1.1 & 439 & 5.09 & 1 \\
\hline 11. & Nicaragua & 7.9 & 358 & 8.75 & 3 \\
\hline 12. & Nigeria & 5.0 & 5,450 & 3.65 & 7 \\
\hline 13. & Pakistan & 1.7 & 2,227 & 2.75 & 4 \\
\hline 14. & Philippines & 1.5 & 1,099 & 4.39 & 4 \\
\hline 15. & Tanzania & 2.4 & 807 & 4.14 & 1 \\
\hline \multicolumn{6}{|c|}{ Upper-middle income } \\
\hline 16. & Albania & 4.8 & 109 & 6.7 & 1 \\
\hline 17. & Argentina & 12.3 & 4,083 & 7.55 & 7 \\
\hline 18. & Brazil & 8.0 & 13,265 & 11.77 & 5 \\
\hline 19. & Bulgaria & 6.6 & 351 & 8.23 & 3 \\
\hline 20. & China & 1.5 & 16,030 & 4.98 & 1 \\
\hline 21. & Colombia & 7.0 & 2,642 & 5.91 & 4 \\
\hline 22. & Ecuador & 6.3 & 773 & 8.39 & 1 \\
\hline 23. & Fiji & 12.6 & 76 & 3.46 & 1 \\
\hline 24. & Georgia & 8.0 & 245 & 8.44 & 1 \\
\hline 25. & Guatemala & 7.0 & 820 & 5.82 & 6 \\
\hline 26. & Iran & 7.9 & 4,870 & 8.10 & 5 \\
\hline 27. & Iraq & 9.4 & 2,263 & 3.31 & 5 \\
\hline 28. & Jordan & 14.8 & 732 & 5.47 & 4 \\
\hline 29. & Lebanon & 11.5 & 457 & 8.02 & 4 \\
\hline 30. & Malaysia & 5.7 & 1,380 & 3.80 & 5 \\
\hline 31. & Mauritius & 7.6 & 78 & 5.75 & 1 \\
\hline 32. & Mexico & 12.6 & 12,235 & 5.47 & 20 \\
\hline 33. & Paraguay & 7.2 & 343 & 8.02 & 3 \\
\hline 34. & Peru & 6.4 & 1,511 & 5.14 & 4 \\
\hline 35. & South Africa & 15.1 & 5,703 & 8.11 & 1 \\
\hline 36. & Sri Lanka & 2.0 & 323 & 3.89 & 3 \\
\hline 37. & St Lucia & 13.0 & 19 & 5.31 & 1 \\
\hline 38. & Thailand & 3.1 & 1,720 & 3.71 & 3 \\
\hline \multicolumn{6}{|c|}{ High income } \\
\hline 39. & Australia & 13.4 & 2,705 & 9.25 & 7 \\
\hline 40. & Austria & 6.9 & 489 & 10.44 & 2 \\
\hline 41. & Barbados & 14.4 & 33 & 6.96 & 4 \\
\hline 42. & Belgium & 6.4 & 590 & 10.04 & 2 \\
\hline 43. & Canada & 13.0 & 3,993 & 10.53 & 4 \\
\hline 44. & Chile & 12.5 & 1,879 & 8.53 & 8 \\
\hline 45. & Germany & 7.3 & 4,827 & 11.14 & 3 \\
\hline 46. & Greece & 8.8 & 777 & 8.45 & 4 \\
\hline 47. & Hong Kong & 1.6 & 100 & 6.2 & 7 \\
\hline 48. & Ireland & 11.4 & 427 & 7.38 & 7 \\
\hline
\end{tabular}




\begin{tabular}{|c|c|c|c|c|c|}
\hline 49. & Israel & 9.0 & 556 & 7.31 & 4 \\
\hline 50. & Italy & 7.1 & 3,495 & 8.94 & 4 \\
\hline 51. & Kuwait & 17.1 & 539 & 3.90 & 6 \\
\hline 52. & Netherlands & 5.9 & 810 & 10.36 & 7 \\
\hline 53. & New Zealand & 15.1 & 558 & 9.22 & 2 \\
\hline 54. & Norway & 9.5 & 415 & 10.50 & 1 \\
\hline 55. & Oman & 11.4 & 354 & 4.29 & 5 \\
\hline 56. & Portugal & 6.2 & 525 & 9.08 & 1 \\
\hline 57. & Qatar & 19.4 & 369 & 3.08 & 2 \\
\hline 58. & Saudi Arabia & 16.1 & 3,763 & 5.74 & 6 \\
\hline 59. & Singapore & 1.2 & 60 & 4.47 & 2 \\
\hline 60. & South Korea & 0.6 & 276 & 7.34 & 3 \\
\hline 61. & Spain & 8.6 & 3,269 & 8.97 & 3 \\
\hline 62. & Sweden & 7.0 & 555 & 10.93 & 3 \\
\hline 63. & Switzerland & 6.6 & 471 & 12.25 & 3 \\
\hline 64. & Taiwan & 1.5 & 287 & 6.14 & 3 \\
\hline 65. & UAE & 15.0 & 1,079 & 3.52 & 8 \\
\hline 66. & UK England & \multirow{2}{*}{12.8} & 5,990 & \multirow{2}{*}{9.8} & 7 \\
\hline 67. & UK Scotland & & 525 & & 3 \\
\hline 68. & USA & 20.1 & 52,381 & 17.07 & 8 \\
\hline & & & & & 274 \\
\hline
\end{tabular}

(1) World Obesity Federation estimates ${ }^{5}$

(2) World Bank 2019: https://data.worldbank.org/indicator/SH.XPD.CHEX.GD.ZS plus Hong Kong: https://www.dh.gov.hk/english/statistics/statistics_hs/files/Health_Statistics pamphlet_E.pdf and Taiwan: https://2016.export.gov/industry/health/healthcareresourceguide/eg_main_108622.asp\#P97_12326. 
Table 2: Self-declared status of respondents

\begin{tabular}{|l|c|c|c|c|c|c|c|c|}
\hline & All & LLMI & UMI & HI & $\begin{array}{c}\text { Low } \\
\text { HCE }\end{array}$ & $\begin{array}{c}\text { High } \\
\text { HCE }\end{array}$ & $\begin{array}{c}\text { Lower } \\
\text { prevalence }\end{array}$ & $\begin{array}{c}\text { Higher } \\
\text { prevalence }\end{array}$ \\
\hline Number of countries & $\mathbf{6 8}$ & $\mathbf{1 5}$ & $\mathbf{2 3}$ & $\mathbf{3 0}$ & $\mathbf{2 2}$ & $\mathbf{2 2}$ & $\mathbf{2 2}$ & $\mathbf{2 2}$ \\
\hline $\begin{array}{l}\text { Physician / clinician / } \\
\text { internal medicine }\end{array}$ & 37 & 9 & 10 & 18 & 14 & 16 & 12 & 15 \\
\hline GP / family physician & 28 & 4 & 5 & 9 & 9 & 16 & 10 & 8 \\
\hline Bariatric surgeon & 27 & 5 & 9 & 13 & 6 & 10 & 8 & 5 \\
\hline Endocrinologist & 26 & 4 & 9 & 13 & 7 & 8 & 8 & 8 \\
\hline Paediatrician & 10 & 1 & 2 & 7 & 3 & 4 & 3 & 6 \\
\hline Nurse & 4 & 2 & 1 & 12 & 2 & 2 & 2 & 2 \\
\hline Nutritionist / dietitian & 59 & 10 & 34 & 15 & 15 & 29 & 19 & 9 \\
\hline Physical activity specialist & 7 & 4 & 2 & 1 & 5 & 2 & 6 & 1 \\
\hline $\begin{array}{l}\text { Psychologist, or health } \\
\text { promotion specialist }\end{array}$ & 13 & 2 & 3 & 8 & 4 & 6 & 3 & 6 \\
\hline Pharmacist & 4 & 1 & 1 & 2 & 2 & 1 & 1 & 1 \\
\hline $\begin{array}{l}\text { Advocacy or civil } \\
\text { organisation staff member }\end{array}$ & 8 & 3 & 0 & 5 & 4 & 4 & 4 & 4 \\
\hline Patient & 10 & 1 & 2 & 7 & 1 & 7 & 2 & 13 \\
\hline $\begin{array}{l}\text { Researcher / student / } \\
\text { unspecified }\end{array}$ & 40 & 10 & 11 & 19 & 11 & 15 & 12 & 5 \\
\hline Total & 274 & 56 & 89 & 129 & 83 & 120 & & 91 \\
\hline
\end{tabular}

LLMI: Low and lower-middle income countries; UMI: Upper-middle income countries; HI: High income countries. Low HCE: lowest tertile for health care expenditure; High HCE: highest tertile for health care expenditure.

Lower prevalence: lowest tertile for prevalence of severe obesity; Higher prevalence: highest tertile for prevalence of severe obesity. 
Table 3: Number of countries claiming 'yes' for specified obesity care issues

Data shown are number of countries in which a consensus of respondents stated 'YES'.

\begin{tabular}{|c|c|c|c|c|c|c|c|c|c|}
\hline & & All & $\begin{array}{c}\mathbf{L} \mathbf{\& L} \\
\mathbf{M I}\end{array}$ & UMI & HI & $\begin{array}{l}\text { Low } \\
\text { HCE }\end{array}$ & $\begin{array}{l}\text { High } \\
\text { HCE }\end{array}$ & $\begin{array}{c}\text { Lower } \\
\text { prevalen } \\
\text { ce }\end{array}$ & $\begin{array}{c}\text { Higher } \\
\text { prevalence }\end{array}$ \\
\hline \multicolumn{2}{|c|}{ Total number of countries } & 68 & 15 & 23 & 30 & 22 & 23 & 22 & 23 \\
\hline \multirow{2}{*}{\multicolumn{2}{|c|}{ Professional guidelines for treatment }} & 42 & 6 & 15 & 21 & 13 & 17 & 14 & 12 \\
\hline & & & \multicolumn{3}{|c|}{$\mathrm{X} 2=3.99, \mathrm{p}=0.14$} & \multicolumn{2}{|c|}{$\mathrm{X} 2=1.11, \mathrm{p}=0.29$} & \multicolumn{2}{|c|}{$\mathrm{X} 2=0.61, \mathrm{p}=0.44$} \\
\hline \multicolumn{10}{|c|}{ Adequate training for ... } \\
\hline & Nutritionist/dietitian & 29 & 5 & 12 & 12 & 10 & 8 & 10 & 10 \\
\hline & GP/family physician & 17 & 2 & 7 & 8 & 7 & 3 & 7 & 6 \\
\hline & Bariatric surgeon & 16 & 1 & 4 & 11 & 3 & 5 & 5 & 7 \\
\hline & Endocrinologist & 11 & 2 & 5 & 4 & 3 & 2 & 3 & 2 \\
\hline & Nurse & 11 & 0 & 5 & 6 & 2 & 5 & 1 & 6 \\
\hline & $\begin{array}{l}\text { Physical activity } \\
\text { specialist }\end{array}$ & 11 & 2 & 4 & 5 & 3 & 3 & 6 & 4 \\
\hline & Psychologist & 8 & 1 & 3 & 4 & 1 & 4 & 3 & 2 \\
\hline & Internal medicine & 7 & 0 & 3 & 4 & 1 & 2 & 2 & 1 \\
\hline & Paediatrics & 4 & 0 & 1 & 3 & 0 & 3 & 1 & 1 \\
\hline & & & \multicolumn{3}{|c|}{$\mathrm{w}=0.72, \mathrm{p}<0.05$} & \multicolumn{2}{|c|}{$\mathrm{r}=0.35, \mathrm{~ns}$} & \multicolumn{2}{|c|}{$\mathrm{r}=0.66, \mathrm{p}<0.05$} \\
\hline \multicolumn{10}{|c|}{ Access to care services via ... } \\
\hline & GP / Primary care & 36 & 4 & 11 & 21 & 11 & 14 & 8 & 17 \\
\hline & & & \multicolumn{3}{|c|}{$\mathrm{X} 2=7.90, \mathrm{p}<0.02$} & \multicolumn{2}{|c|}{$X 2=0.54, p=0.46$} & \multicolumn{2}{|c|}{$\mathrm{X} 2=6.42, \mathrm{p}<0.02$} \\
\hline & $\begin{array}{l}\text { Following } \\
\text { complications }\end{array}$ & 30 & 10 & 8 & 12 & 10 & 9 & 10 & 10 \\
\hline & & & \multicolumn{3}{|c|}{$\mathrm{X} 2=4.11, \mathrm{p}=0.13$} & \multicolumn{2}{|c|}{$\mathrm{X} 2=0.18, \mathrm{p}=0.67$} & \multicolumn{2}{|c|}{$\mathrm{X} 2=0.02, \mathrm{p}=0.89$} \\
\hline & Specialists / hospital & 10 & 1 & 4 & 5 & 3 & 3 & 3 & 4 \\
\hline & Screening & 7 & 0 & 1 & 6 & 3 & 3 & 2 & 4 \\
\hline \multicolumn{10}{|c|}{ Reasons for leaving services ... } \\
\hline & No referral offered & 32 & 6 & 10 & 16 & 11 & 11 & 12 & 14 \\
\hline & Lack of care pathway & 26 & 7 & 10 & 9 & 9 & 7 & 9 & 9 \\
\hline & Treatment failure & 19 & 2 & 6 & 11 & 4 & 8 & 4 & 8 \\
\hline & $\begin{array}{l}\text { Lack of motivation or } \\
\text { poor compliance }\end{array}$ & 17 & 2 & 4 & 11 & 3 & 6 & 3 & 5 \\
\hline & Cost & 11 & 1 & 4 & 6 & 1 & 5 & 0 & 6 \\
\hline & Lost to follow up & 11 & 1 & 3 & 7 & 3 & 4 & 4 & 4 \\
\hline & Long waiting list & 7 & 0 & 3 & 4 & 0 & 2 & 0 & 4 \\
\hline & $\begin{array}{l}\text { Stigma or perceived } \\
\text { exclusion }\end{array}$ & 5 & 1 & 3 & 1 & 2 & 1 & 2 & 2 \\
\hline & Distance from home & 2 & 0 & 1 & 1 & 0 & 0 & 0 & 1 \\
\hline
\end{tabular}

LLMI: Low and lower-middle income countries; UMI: Upper-middle income countries; HI: High income countries. Low HCE: lowest tertile for health care expenditure; High HCE: highest tertile for health care expenditure.

Lower prevalence: lowest tertile for prevalence of severe obesity; Higher prevalence: highest tertile for prevalence of severe obesity.

$\mathrm{X} 2$ is Chi squared, w is Kendall's coefficient of concordance, $\mathrm{r}$ is Spearman's rank correlation coefficient 
Table 4: Ratings on obesity care services

Mean rating value (number of countries giving a consensus response)

$(0=$ 'no' or 'poor'; $10=$ 'yes' or 'excellent')

\begin{tabular}{|c|c|c|c|c|c|c|c|c|}
\hline & All & L\&LMI & UMI & HI & Low HCE & $\begin{array}{l}\text { High } \\
\text { HCE }\end{array}$ & $\begin{array}{c}\text { Lower } \\
\text { prevalenc } \\
\mathrm{e}\end{array}$ & $\begin{array}{c}\text { Higher } \\
\text { prevalenc } \\
\mathrm{e} \\
\end{array}$ \\
\hline $\begin{array}{l}\text { Number of } \\
\text { countries }\end{array}$ & 68 & 15 & 23 & 30 & 22 & 23 & 22 & 23 \\
\hline $\begin{array}{l}\text { Rating of } \\
\text { national } \\
\text { health system } \\
\text { dealing with } \\
\text { obesity }\end{array}$ & $4.2(67)$ & $\begin{array}{c}3.3 \\
(15)\end{array}$ & $4.5(23)$ & $4.4(29)$ & $\begin{array}{l}4.7 \\
(22)\end{array}$ & $\begin{array}{l}3.5 \\
(22)\end{array}$ & $\begin{array}{c}4.8 \\
(21)\end{array}$ & $\begin{array}{c}4.4 \\
(23)\end{array}$ \\
\hline & & \multicolumn{3}{|c|}{$\mathrm{X} 2=3.52, \mathrm{p}=0.17$} & \multicolumn{2}{|c|}{$\mathrm{X} 2=6.36, p=0.01$} & \multicolumn{2}{|c|}{$\mathrm{X} 2=0.61, \mathrm{p}=0.44$} \\
\hline $\begin{array}{l}\text { Availability } \\
\text { of services in } \\
\text { urban areas }\end{array}$ & $4.5(65)$ & $\begin{array}{l}3.5 \\
(14)\end{array}$ & $4.7(23)$ & $\begin{array}{c}4.9 \\
(28)\end{array}$ & $\begin{array}{l}4.5 \\
(22)\end{array}$ & $4.4(21)$ & $\begin{array}{l}4.2 \\
(22)\end{array}$ & $\begin{array}{c}5.0 \\
(21)\end{array}$ \\
\hline & & \multicolumn{3}{|c|}{$\mathrm{X} 2=3.27, \mathrm{p}=0.19$} & \multicolumn{2}{|c|}{$\mathrm{X} 2=0.02, \mathrm{p}=0.88$} & \multicolumn{2}{|c|}{$\mathrm{X} 2=6.29, \mathrm{p}=0.01$} \\
\hline $\begin{array}{l}\text { Availability } \\
\text { of services in } \\
\text { rural areas }\end{array}$ & $2.3(59)$ & $\begin{array}{c}1.2 \\
(13)\end{array}$ & $2.2(23)$ & $3.1(23)$ & $\begin{array}{l}1.8 \\
(18)\end{array}$ & $2.4(20)$ & $\begin{array}{l}1.9 \\
(19)\end{array}$ & $\begin{array}{c}3.0 \\
(19)\end{array}$ \\
\hline & & \multicolumn{3}{|c|}{$\mathrm{X} 2=2.33, \mathrm{p}=0.31$} & \multicolumn{2}{|c|}{$\mathrm{X} 2=1.80, \mathrm{p}=0.17$} & \multicolumn{2}{|c|}{$\mathrm{X} 2=3.59, \mathrm{p}=0.06$} \\
\hline $\begin{array}{l}\text { Comparison } \\
\text { of urban and } \\
\text { rural services }\end{array}$ & $\begin{array}{c}\mathrm{X} 2=67.17 \\
\mathbf{p}<0.001\end{array}$ & $\begin{array}{c}\mathbf{X} 2=18.99 \\
\mathbf{p}<0.001\end{array}$ & $\begin{array}{c}\mathrm{X} 2=31.23, \\
\mathbf{p}<0.001\end{array}$ & $\begin{array}{c}\mathbf{X} 2=17.05 \\
\mathbf{p}<0.001\end{array}$ & $\begin{array}{c}\mathrm{X} 2=32.33 \\
\mathrm{p}<0.001\end{array}$ & $\begin{array}{c}X 2=18.86 \\
p<0.001\end{array}$ & $\begin{array}{c}\mathrm{X} 2=23.96 \\
\mathbf{p}<0.001\end{array}$ & $\begin{array}{c}\mathrm{X} 2=17.32 \\
\mathbf{p}<0.001\end{array}$ \\
\hline $\begin{array}{l}\text { Government } \\
\text { moving } \\
\text { towards } \\
\text { defining } \\
\text { obesity a } \\
\text { disease }\end{array}$ & $5.0(68)$ & $\begin{array}{c}3.8 \\
(15)\end{array}$ & $5.4(23)$ & $5.2(30)$ & $\begin{array}{l}5.0 \\
(22)\end{array}$ & $4.2(23)$ & $\begin{array}{c}5.2 \\
(22)\end{array}$ & $\begin{array}{l}5.5 \\
(23)\end{array}$ \\
\hline & & \multicolumn{3}{|c|}{$\mathrm{X} 2=4.94, \mathrm{p}=0.08$} & \multicolumn{2}{|c|}{$\mathrm{X} 2=3.09, p=0.08$} & \multicolumn{2}{|c|}{$\mathrm{X} 2=0.39, \mathrm{p}=0.53$} \\
\hline $\begin{array}{l}\text { Health care } \\
\text { providers } \\
\text { moving } \\
\text { towards } \\
\text { defining } \\
\text { obesity a } \\
\text { disease }\end{array}$ & $4.9(68)$ & $\begin{array}{l}4.1 \\
(15)\end{array}$ & $4.8(23)$ & $5.3(30)$ & $\begin{array}{l}5.0 \\
(22)\end{array}$ & $4.6(23)$ & $\begin{array}{l}5.0 \\
(22)\end{array}$ & $\begin{array}{c}5.1 \\
(23)\end{array}$ \\
\hline & & \multicolumn{3}{|c|}{$X 2=5.66, p=0.06$} & \multicolumn{2}{|c|}{$\mathrm{X} 2=0.69, \mathrm{p}=0.41$} & \multicolumn{2}{|c|}{$\mathrm{X} 2=0.03, \mathrm{p}=0.85$} \\
\hline
\end{tabular}

Data shown are unweighted means of each county's average rating.

$\mathrm{X} 2$ is Chi squared.

LLMI: Low and lower-middle income countries; UMI: Upper-middle income countries; HI: High income countries.

Low HCE: lowest tertile for health care expenditure; High HCE: highest tertile for health care expenditure.

Lower prevalence: lowest tertile for prevalence of severe obesity; Higher prevalence: highest tertile for prevalence of

severe obesity.

$\mathrm{X} 2$ is Chi squared 
Table 5: Perceived barriers to treatment

Sum of 'top five' responses

\begin{tabular}{|c|c|c|c|c|c|c|c|c|}
\hline & All & rank & LLMI & rank & UMI & rank & HI & rank \\
\hline Lack of political will and interest & 7.5 & 1 & 2.4 & 1 & 2.9 & 1 & 2.2 & 5 \\
\hline Lack of training for HCP's and lack of trained HCP's & 6.1 & 2 & 1.3 & 3 & 1.8 & 4 & 3.1 & 1 \\
\hline High cost of out of pocket payments & 5.6 & 3 & 1.3 & 4 & 1.9 & 3 & 2.5 & 3 \\
\hline Poor health literacy and behaviour & 5.2 & 4 & 1.5 & 2 & 1.3 & 7 & 2.4 & 4 \\
\hline Obesity not recognised as a disease & 4.7 & 5 & 1.3 & 5 & 1.3 & 6 & 2.2 & 6 \\
\hline $\begin{array}{l}\text { Lack of investment in health system; lack of funding } \\
\text { for coverage }\end{array}$ & 4.7 & 6 & 0.8 & 6 & 2.1 & 2 & 1.7 & 7 \\
\hline Stigma, blame and belief in individual responsibility & 3.2 & 7 & 0.0 & 30 & 0.6 & 15 & 2.7 & 2 \\
\hline Food costs; obesogenic food environments & 3.1 & 8 & 0.6 & 8 & 1.7 & 5 & 0.8 & 13 \\
\hline Cultural norms and traditions around obesity & 2.5 & 9 & 0.6 & 7 & 0.8 & 10 & 1.1 & 9 \\
\hline Lack of evidence, monitoring and research & 2.3 & 10 & 0.3 & 12 & 1.3 & 8 & 0.7 & 15 \\
\hline Poor availability of pharmaceutical treatments & 1.8 & 11 & 0.2 & 22 & 0.8 & 9 & 0.9 & 11 \\
\hline Food industry influence on environment and narrative & 1.8 & 12 & 0.5 & 9 & 0.6 & 13 & 0.7 & 14 \\
\hline Lack of treatment facilities; long waiting lists & 1.7 & 13 & 0.1 & 26 & 0.5 & 17 & 1.1 & 8 \\
\hline $\begin{array}{l}\text { Failure to recognise treatment options; excess focus on } \\
\text { surgery }\end{array}$ & 1.6 & 14 & 0.1 & 24 & 0.4 & 21 & 1.1 & 10 \\
\hline Poor adherence to treatment; fear of treatment & 1.5 & 15 & 0.2 & 15 & 0.7 & 12 & 0.6 & 17 \\
\hline Fragmented or failing health system & 1.5 & 16 & 0.4 & 10 & 0.5 & 16 & 0.5 & 20 \\
\hline $\begin{array}{l}\text { Lack of opportunity for physical activity or safe active } \\
\text { transport }\end{array}$ & 1.3 & 17 & 0.2 & 17 & 0.5 & 18 & 0.6 & 18 \\
\hline Obesogenic environment (not specified) & 1.3 & 18 & 0.2 & 19 & 0.5 & 19 & 0.6 & 16 \\
\hline Lack of multi-disciplinary teams & 1.1 & 19 & 0.0 & 29 & 0.6 & 14 & 0.5 & 19 \\
\hline Social determinants of health; social deprivation & 1.1 & 20 & 0.3 & 14 & 0.4 & 20 & 0.4 & 22 \\
\hline Lack of time with GP; lack of assessment and referral & 1.0 & 21 & 0.2 & 20 & 0.0 & 29 & 0.8 & 12 \\
\hline Obesity a sign of wealth and status & 0.9 & 22 & 0.2 & 21 & 0.7 & 11 & 0.0 & 30 \\
\hline $\begin{array}{l}\text { Lack of treatment guidelines or pathway; failure to } \\
\text { follow guidelines }\end{array}$ & 0.9 & 23 & 0.2 & 16 & 0.2 & 24 & 0.5 & 21 \\
\hline $\begin{array}{l}\text { Health care professional disinterest in obesity training } \\
\text { or treatments }\end{array}$ & 0.8 & 24 & 0.3 & 11 & 0.1 & 26 & 0.3 & 24 \\
\hline $\begin{array}{l}\text { Patients' lack of knowledge of available treatment } \\
\text { options }\end{array}$ & 0.7 & 25 & 0.1 & 25 & 0.2 & 23 & 0.4 & 23 \\
\hline Lack of patient support groups or national associations & 0.6 & 26 & 0.3 & 13 & 0.1 & 25 & 0.2 & 27 \\
\hline Economic crisis affecting services & 0.6 & 27 & 0.0 & 28 & 0.3 & 22 & 0.3 & 25 \\
\hline New technology not supported or reimbursed & 0.4 & 28 & 0.2 & 18 & 0.1 & 27 & 0.1 & 28 \\
\hline Use of inappropriate 'treatments' & 0.3 & 29 & 0.0 & 27 & 0.1 & 28 & 0.2 & 26 \\
\hline Unrealistic expectations of treatment & 0.2 & 30 & 0.2 & 23 & 0.0 & 30 & 0.1 & 29 \\
\hline & & & \multicolumn{6}{|c|}{$w=0.73, p<0.001$} \\
\hline
\end{tabular}

LLMI: Low and lower-middle income countries; UMI: Upper-middle income countries; HI: High income countries $w$ is Kendall's coefficient of concordance 
Clinical care for obesity: a preliminary survey of 68 countries R Jackson Leach et al.

Clinical Obesity, 2020.

\section{Supplementary Material}

\section{Contents}

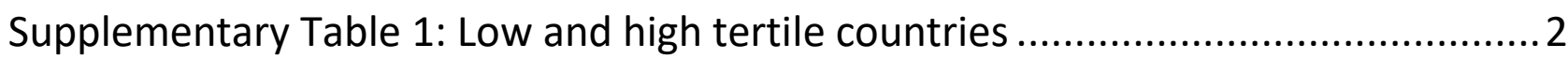

Supplementary material: Interview protocol ............................................................ 3

Supplementary material: Online survey protocol................................................ 6 
Supplementary table 1: Low and high tertile countries

\begin{tabular}{|l|l|l|l|}
\hline $\begin{array}{l}\text { Lower health care } \\
\text { expenditure/GDP }\end{array}$ & $\begin{array}{l}\text { Higher health } \\
\text { care } \\
\text { expenditure/GDP }\end{array}$ & $\begin{array}{l}\text { Lower projected } \\
\text { prevalence of } \\
\text { BMI }>\mathbf{3 4 . 9} \mathbf{~ k g} / \mathbf{m} 2\end{array}$ & $\begin{array}{l}\text { Higher projected } \\
\text { prevalence of BMI } \\
\mathbf{3 4 . 9} \mathbf{~ k g} / \mathbf{m} 2\end{array}$ \\
\hline Bangladesh & Australia & Albania & Argentina \\
\hline Cameroon & Austria & Bangladesh & Australia \\
\hline China & Belgium & Cameroon & Barbados \\
\hline Egypt & Brazil & China & Canada \\
\hline Ethiopia & Bulgaria & Ethiopia & Chile \\
\hline Fiji & Canada & Hong Kong & Egypt \\
\hline India & Chile & India & Fiji \\
\hline Indonesia & Ecuador & Indonesia & Ireland \\
\hline Iraq & Georgia & Kenya & Jordan \\
\hline Kenya & Germany & Malaysia & Kuwait \\
\hline Kuwait & Greece & Myanmar & Lebanon \\
\hline Malaysia & Italy & Netherlands & Mexico \\
\hline Nigeria & Netherlands & Nigeria & New Zealand \\
\hline Oman & New Zealand & Pakistan & Norway \\
\hline Pakistan & Nicaragua & Philippines & Oman \\
\hline Philippines & Norway & Portugal & Qatar \\
\hline Qatar & Portugal & Singapore & Saudi Arabia \\
\hline Singapore & Spain & South Korea & South Africa \\
\hline Sri Lanka & Sweden & Sri Lanka & St Lucia \\
\hline Tanzania & Switzerland & Taiwan & UAE \\
\hline Thailand & UK & Tanzania & UK \\
\hline UAE & USA & Thailand & USA \\
\hline & & & \\
\hline
\end{tabular}




\section{Supplementary material: Interview protocol}

Note: Questions in bold are key questions that all interviewees should be asked. Other questions are 'nice to have'

\section{Obesity as a Disease}

"Please rate between $\mathbf{0}$ - 10 where your country's GOVERNMENT is in the journey towards defining 'Obesity as a disease' ( $0=$ not considered a disease, 10 = Obesity defined as a disease). Please explain your rating.

"Please rate between 0 - 10 where your country's HEALTHCARE PROVIDER is in the journey towards defining

'Obesity as a disease' ( $0=$ not considered a disease, $10=$ Obesity defined as a disease). Please explain your rating.

"Where is your country in recognising obesity as a disease in respect to medical societies?

"Is Obesity described as a disability in terms of employment? If yes, is comprehensive or on an ad hoc basis?

\section{Finance}

What obesity interventions are covered by government funding and/or social insurance (if any)?

"How is obesity treatment generally funded in practice? Government funding, insurance or out of pocket? Please consider the case for all interventions.

"Please identify what your country is doing very well or very poorly in terms of financial support for obesity prevention/treatment/management?

\section{Prevention}

"Please outline what your country is doing to PREVENT obesity?

Please rate between $\mathbf{0}-\mathbf{1 0}$ how your health system is working in terms of obesity prevention and treatment $(0=$ not working at all, $10=$ working well). Please explain your rating.

"How could obesity be better prevented in your country? (Up to 3 suggestions)

\section{Obesity Treatment}

"At what threshold of obesity do individuals become ELIGIBLE for obesity treatment? E.g. BMI $\geq 30, \geq 35$ or $\geq 40$ $\mathrm{kg} / \mathrm{m}^{2}$ (with or without related co-morbidities)."

"In reality, do individuals actually receive treatment when they should? If not, why not and at what level of BMI do they receive treatment? E.g. BMI $\geq 30, \geq 35$ or $\geq 40 \mathrm{~kg} / \mathrm{m}^{2}$ (with or without related co-morbidities). "

"How do people with obesity usually enter the health system \& who doesn't enter the system?

"How do people with obesity usually leave/fall out of the health system?

What do you consider to be the Top 5 barriers to obesity treatment in your country?

Describe the typical clinical pathway. How is someone treated in primary, secondary and tertiary care?

\section{Primary Care Strategy}

Is it routine to take height and weight measurements in consultation and do they record BMI? Is the information held on a national database or simply kept in medical records? 
"Is a discussion held if they are found to be at an unhealthy BMI? If a discussion is not held, what reasons are given for not holding a conversation?

\section{NCD National Strategies}

Does your country have a national strategy on NCDs? Does it have an implementation guide?

Does the national strategy include obesity? If so, how does it include it? Is there anything related to obesity that is working particularly well or poorly? Please explain and give examples.

If your country does not have an NCD strategy, please give your views on why this is the case.

\section{Health Professionals}

"Please rate between 0 - 10 the availability of suitably qualified obesity treatment professionals in urban areas. $(0=$ not available, $\mathbf{1 0}$ = widely and easily available to all) If specific professions are in short supply please identify:"

"Please rate between 0 - 10 the availability of suitably qualified obesity treatment professionals in rural areas. $(0=$ not available, $\mathbf{1 0}$ = widely and easily available to all) If specific professions are in short supply please identify:"

\section{Specialist Obesity Training}

Is specialist obesity training available across the Health System? What professions are included?

Is specialist obesity training up to date and appropriate? Is it mandatory?

If specialist obesity training is available, are trainees funded to train or are they required to self fund?

Is there formal recognition available for obesity specialisation?

If specialist obesity training is not available, please could you suggest why this may be the case.

Are there any gaps/specific needs not currently addressed in the specialist training?

Are you aware of any other specialist training available to healthcare professionals, perhaps online or abroad? If so, please could you specify?

\section{Recommendations/Guidelines}

Do any government bodies have any obesity-related treatment recommendations or guidelines for adults or children? Are they current? Evidence-based? Please obtain details or a link.

Do any non-government bodies have any obesity-related treatment recommendations or guidelines for adults or children? Are they current? Evidence-based? Please obtain details or a link.

If your country has guidelines, please rate the uptake amongst healthcare practitioners $(0=$ no uptake, $10=$ complete uptake). Please explain your rating.

\section{Political Influences}

"What Fiscal measures have been put in place to protect/assist/inform the population? 
Cultural Influences

"What are the cultural considerations in terms of obesity?

Patient Networks

"Do your patients advocate in any way for themselves? Are they visible or vocal? Do they have a network?

Does your country have any local Patient organisations? 


\section{Supplementary material: Online survey protocol}

We encourage responses from all professions - clinicians, researchers, students, policy-makers and more. No questions are mandatory to reflect this - just answer as much as you can!

Please note that while we ask for your details, responses are pooled and presented anonymously.

1 Please complete your details

Name:

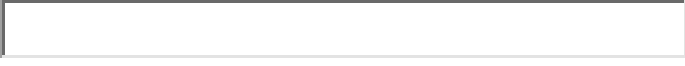

Professional Role:

Email:

Country:

2 Please rate between 0 - 10 where your country's GOVERNMENT is in the journey towards defining 'Obesity as a disease'.

$(0=$ not considered a disease, $10=$ Obesity defined as a disease $)$

0

10

3 Please take a few moments to explain your rating in Question 2

4 Please rate between 0 - 10 where your country's HEALTHCARE PROVIDER is in the journey towards defining 'Obesity as a disease'.

$(0=$ not considered a disease, $10=$ Obesity defined as a disease $)$

0

5Please take a few moments to explain your rating in Question 4 
6 Please rate between 0 - 10 how your health system is working in terms of obesity prevention and treatment.

$(0=$ not working at all, $10=$ working well $)$

7 Please take a few moments to explain your rating in Question 6

8 Please outline what your country is doing to PREVENT obesity? For example, there may be school-led interventions, city-wide interventions or mandatory food labelling.

9Have any fiscal measures been put in place to protect/assist/inform the population around obesity?

10 How could obesity be better prevented in your country?

1.

2.

3.

11 What obesity interventions are covered by government funding and/or social insurance (if any)?

$\Gamma \quad$ Lifestyle and behavioural

$\Gamma$ Pharmacological

$\Gamma$ Surgical

Other (please specify)

12 How is obesity treatment generally funded in practice? Government funding, insurance or out of pocket? E.g. Individuals may pay out of pocket because of long waiting lists for public services. Please consider the case for all interventions.

Lifestyle and behavioural 
Pharmacological

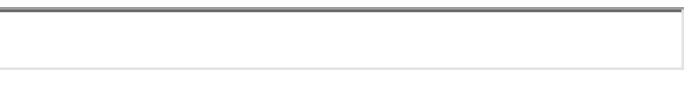

Surgical

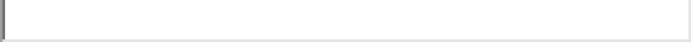

Other (please specify)

13 Please identify what your country is doing very well or very poorly in terms of financial support for obesity prevention/treatment/management?

14 Does your country have a National Strategy on NCDs (non-communicable diseases)?

C Yes

No - Please go to Q17

Unsure / Don't know

15 Does your country's NCD strategy have an implementation guide? Please comment:

16 Is there anything in the NCD strategy related to obesity that is working particularly well or poorly? Please provide details or examples here:

17 If your country does not have an NCD strategy, please give your views on why this is the case (Skip this question if your country has an NCD strategy)

Non-clinicians, please skip this page if unable to answer these questions.

18 What do you consider to be the Top 5 barriers to obesity treatment in your country?

1.

2.

3.

4.

5. 
19 To what extent does an individual have to suffer obesity to be ELIGIBLE for obesity treatment? E.g. BMI $\geq 30, \geq 35$ or $\geq 40 \mathrm{~kg} / \mathrm{m}^{2}$ (with or without related co-morbidities).

Lifestyle and behavioural

Pharmacological

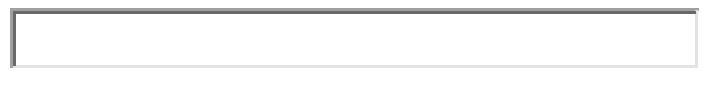

Surgical

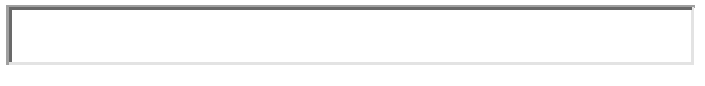

Other (please specify)

20 In reality, do individuals actually receive treatment when they should? If not, why not and at what level of BMI do they receive treatment? E.g. BMI $\geq 30, \geq 35$ or $\geq 40 \mathrm{~kg} / \mathrm{m}^{2}$ (with or without related co-morbidities).

Lifestyle and behavioural

Pharmacological

Surgical

Other (please specify)

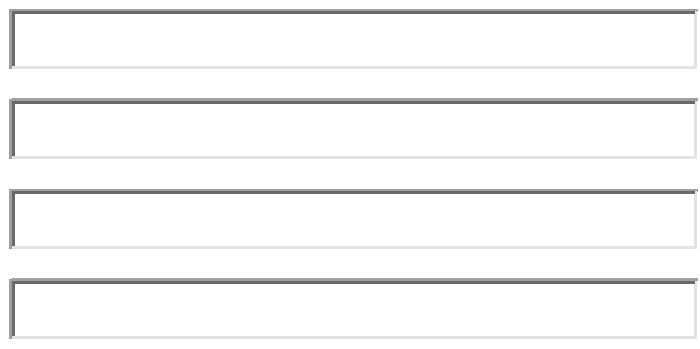

21 How do people with obesity usually enter the health system? Who doesn't enter the system? For example, those living in rural communities may have restricted access to facilities so never enter the health system.

22 Describe the typical clinical pathway. How is someone treated in primary, secondary and tertiary care?

23 How do people with obesity usually leave/fall out of the health system? For example, they may not be referred for specialist obesity treatment or they may successfully lose weight.

24 Please rate between 0 - 10 the availability of suitably qualified obesity treatment professionals in urban areas. 
$(0=$ not available, $10=$ widely and easily available to all $)$

25 If specific professions from Q24 are in short supply please identify below

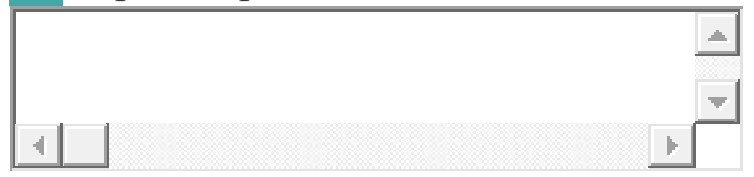

26 Please rate between 0 - 10 the availability of suitably qualified obesity treatment professionals in rural areas.

$(0=$ not available, $10=$ widely and easily available to all $)$

0

10

27 If specific professions from Q26 are in short supply please identify below

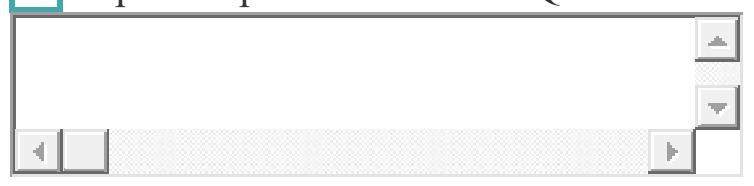

28 Do any government bodies have any obesity-related treatment recommendations or guidelines for adults or children? Please provide details.

Adults

Children

29 Do any non-governmental bodies (e.g. networks, institutes, organisations) have any obesityrelated treatment recommendations or guidelines for adults or children? Please provide details Adults

Children

30 If your country has guidelines, please rate the uptake amongst healthcare practitioners?

$(0=$ no uptake, $10=$ complete uptake $)$ 
31Please take a moment to explain your rating in Question 30.

32 What specialist obesity training is available across the health system?

33 If specialist obesity training is available, is it nationally or regionally available?

34 If specialist obesity training is available, what professions are included?

35 Does your country implement any particularly successful or innovative technologies for tackling obesity? Equally, if you have any experience of any unsuccessful use of technologies please describe this below.

36 Who else should we interview to obtain a good picture of obesity management in your country?

37 Would you be happy to be contacted again about this project and other World Obesity

Federation programmes?

Y Yes

No 